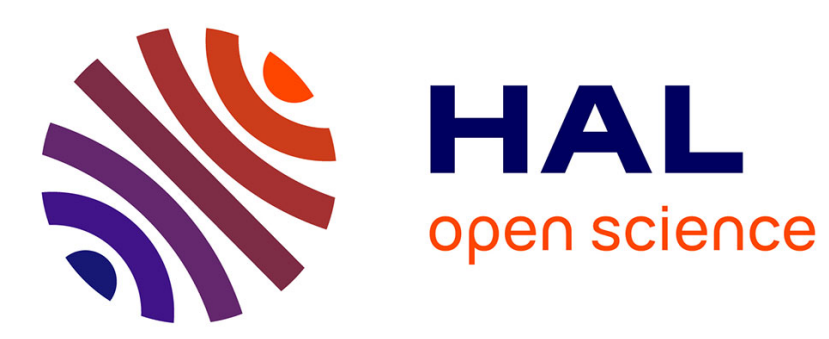

\title{
Adsorptive removal of gaseous formaldehyde at realistic concentrations
}

Irene Lara-Ibeas, Cristina Megias-Sayago, Benoît Louis, Stéphane Le Calvé

\section{To cite this version:}

Irene Lara-Ibeas, Cristina Megias-Sayago, Benoît Louis, Stéphane Le Calvé. Adsorptive removal of gaseous formaldehyde at realistic concentrations. Journal of Environmental Chemical Engineering, 2020, 8 (4), pp.103986. 10.1016/j.jece.2020.103986 . hal-02611244

\section{HAL Id: hal-02611244 \\ https://hal.science/hal-02611244}

Submitted on 9 Dec 2020

HAL is a multi-disciplinary open access archive for the deposit and dissemination of scientific research documents, whether they are published or not. The documents may come from teaching and research institutions in France or abroad, or from public or private research centers.
L'archive ouverte pluridisciplinaire HAL, est destinée au dépôt et à la diffusion de documents scientifiques de niveau recherche, publiés ou non, émanant des établissements d'enseignement et de recherche français ou étrangers, des laboratoires publics ou privés. 


\title{
ADSORPTIVE REMOVAL OF GASEOUS FORMALDEHYDE AT REALISTIC CONCENTRATIONS
}

Irene Lara-Ibeas ${ }^{1}$, Cristina Megías-Sayago ${ }^{2}$, Benoît Louis ${ }^{2}$, Stéphane Le Calvé 1,3 * $^{*}$

${ }^{1}$ ICPEES - Institut de Chimie et Procédés pour 1'Energie, l'Environnement et la Santé, Atmospheric Physical Chemistry Team, UMR 7515 CNRS - Université de Strasbourg - ECPM, 25 rue Becquerel F67087 Strasbourg cedex 2, France

${ }^{2}$ ICPEES - Institut de Chimie et Procédés pour l'Energie, l'Environnement et la Santé, Energy and Fuels for a Sustainable Environment Team, UMR 7515 CNRS - Université de Strasbourg - ECPM, 25 rue Becquerel F-67087 Strasbourg cedex 2, France

${ }^{3}$ In'Air Solutions, 25 rue Becquerel, 67087 Strasbourg, France

* slecalve@unistra.fr; Tel.: +33-3-6885-0368

\begin{abstract}
Due to analytical reasons, adsorption capacity is often determined at very high concentrations which is not representative of a real environment. The aim of this work is to provide experimental data of formaldehyde adsorption capacity at realistic levels ( $164 \mathrm{ppb})$ thanks to a near real-time powerful formaldehyde analyser recently developed in our laboratory. Gaseous formaldehyde breakthrough experiments were conducted on a broad spectrum of materials including carbon, zeolites, metal organic framework and mesoporous silica in order to determine their adsorption capacity. Among these materials, HKUST-1 exhibited the highest adsorption capacity (504 $\mu \mathrm{g} / \mathrm{g}$ ads) followed by MgZSM5 (35 $\mu \mathrm{g} / \mathrm{g}$ ads), SBA-16 (29 $\mu \mathrm{g} / \mathrm{g}$ ads), ZSM-5 (10 - $26 \mu \mathrm{g} / \mathrm{g}$ ads) and Carbopack $®$ B (4 $\mu \mathrm{g} / \mathrm{g}$ ads). In the case of ZSM-5 zeolites, the results revealed that formaldehyde adsorption was related to their aluminium content. The presence of aluminium implies more bridging hydroxyl groups $\mathrm{Si}-(\mathrm{OH})-\mathrm{Al}$ that act as Brønsted acid sites interacting with formaldehyde molecules. Despite the moderate adsorption capacity of ZSM-5 zeolites, they can be considered as promising candidates for gas analysis applications, for example where a good analytical blank is essential for accurate measurements.
\end{abstract}


Keywords: formaldehyde, adsorption, zeolites, indoor air, gas analysis, realistic concentrations.

\section{Introduction}

Formaldehyde is one of the most common toxic pollutants found in indoor air [1]. In closed environments, a broad spectrum of sources has been identified as responsible for its emission as candles, paints or wood-based materials as well as sources related to the occupants' activity like smoking or cooking [2]. These sources usually lead to indoor formaldehyde concentrations from 2 to 15 times higher than those measured outdoors [3]. Formaldehyde has adverse effects on human health, being considered carcinogenic (Group 1) by IARC since 2006. Short-term exposure can provoke throat, nose and eye irritation and headache whereas the long-term exposure effects are more damaging with the appearance of pneumonia, asthma and nasopharyngeal cancer [4-6]. Consequently, new legislations concerning formaldehyde have been developed in several countries in order to limit human exposure and protect public health. In the European Union, a short-term guideline of $100 \mu \mathrm{g} \cdot \mathrm{m}^{-3}$ formaldehyde concentration is recommended which should not be exceeded at any $30 \mathrm{~min}$ interval during a day [7]. Nevertheless, in some countries, as is the case of France, the legislation concerning indoor air quality in public buildings became stricter. According to the Decree no. 2011-1727 of December 2011, a limit value of $30 \mu \mathrm{g} \cdot \mathrm{m}^{-3}$ was fixed for formaldehyde long-term exposure from 2015 , value that will be decreased to $10 \mu \mathrm{g} \mathrm{m}^{-3}$ from 2023 [8]. Motivated by this stringent regulation, the development of both sensitive analytical devices able to monitor formaldehyde as well as effective low cost techniques to remove it even at low concentrations have attracted great interest in the last years [5,9].

Adsorptive methods are usually employed for both gaseous pollutants removal and sample preconcentration in gas analysis. However, common adsorbents are often not effective for formaldehyde adsorption due to the high polarity and small size of this molecule. In this regard, consequent efforts have been made to investigate formaldehyde adsorption properties over a wide variety of commercially available and synthesized materials [10-14] (summarized in Table 1). Nevertheless, most of these works 
were performed at rather unrealistic formaldehyde levels (1 to $150 \mathrm{ppm}$ ) [10,11,13,14], thus rendering those experimental results not fully representative of the performances in real environments. Indeed, the adsorption capacity depends on the gas partial pressure, this relationship being not linear in all the partial pressure range. According to Henry's law [15], it can be assumed that the adsorption capacity increases linearly with the partial pressure at very low concentrations, however, previous studies carried out over different materials have demonstrated that formaldehyde adsorption follows a non-linear tendency [10,11]. Carter et al. [11] studied formaldehyde adsorption in the ppm range over different activated carbonaceous materials. In the high-pressure region (concentration $\sim 25 \mathrm{ppm}$ ), ACF (activated carbon fibers) exhibited the highest adsorption capacity followed by GAC1 (all-purpose granular AC) and GACF (commercial granular AC for HCHO gas-phase removal). However, a completely different behaviour was observed at lower concentrations $(\sim 3.5 \mathrm{ppm})$ where the highest adsorption capacity was ascribed to GACF followed by ACF and GAC1. Similar results were reported by Bellat et al. [10] over AC (activated carbon), MIL-53 (metal organic framework) and SBA-15 (mesoporous silica). In this case, AC showed poor adsorption capacity compared to MIL-53 at formaldehyde partial pressure of 2 $\mathrm{hPa}(\sim 2000 \mathrm{ppm})$. However, almost identical adsorption capacities were registered when formaldehyde partial pressure approached more realistic levels. These results reveal the importance of using concentrations as close as possible to the real ones to accurately assess the adsorption performance for real-world applications. In this regard, there is an obvious lack of experimental data in the literature on formaldehyde adsorption at ppb levels, which are necessary to properly evaluate the materials for either pollutant removal or potential gas analysis applications. Therefore, the objective of this study is to provide accurate information on the adsorption performance of a series of materials at realistic formaldehyde concentrations.

In this work, formaldehyde adsorption was investigated over a series of porous materials at ppb levels. On the one hand, three commercial adsorbents differing in their textural properties and chemical composition were evaluated, named Carbopack ${ }^{\circledR}$ B, HKUST-1 and SBA-16, respectively. On the other hand, three synthetic H-ZSM-5 zeolites with Si/Al molar ratios (SAR) of 198, 132 and 79 were assessed which additionally allow evaluating the influence of the aluminium content on the adsorption process. 
Finally, commercially available CBV3020E zeolite (Zeolyst, SAR $=15$ ) was exchanged with Mg and both materials were tested in formaldehyde adsorption. The obtained experimental data were compared with those found in the literature. 
Table 1. Formaldehyde adsorption capacities of various materials obtained in previous studies classified in ascending order of $K_{H}$ value.

\begin{tabular}{|c|c|c|c|c|c|c|c|c|c|c|}
\hline Adsorbent & $\begin{array}{c}\text { Adsorbent } \\
\text { Type }\end{array}$ & $\begin{array}{c}S_{B E T} \\
\left(\mathbf{m}^{2} / \mathbf{g}\right)\end{array}$ & $\begin{array}{c}V_{\text {total }} \\
(\mathrm{mL} / \mathrm{g})\end{array}$ & $\begin{array}{l}\text { Pore size } \\
\quad(\mathbf{n m})\end{array}$ & $\begin{array}{c}\text { Concentration } \\
(\text { ppm) }\end{array}$ & $\begin{array}{c}\text { Partial } \\
\text { pressure (Pa) }\end{array}$ & $\begin{array}{l}\text { Temperature } \\
\left({ }^{\circ} \mathbf{C}\right)\end{array}$ & $\begin{array}{c}\text { Adsorption } \\
\text { Capacity } \\
\text { (mg/g ads) }\end{array}$ & $\begin{array}{c}K_{H} \\
(\mathrm{~mol} / \mathrm{kg} \mathrm{Pa})\end{array}$ & Reference \\
\hline $\mathrm{ACF}$ & $\mathrm{AC}$ & 860 & 0.34 & 0.53 & 3.65 & 0.334 & 26 & 52.30 & 5.221 & (Carter et al., 2011) \\
\hline $\mathrm{NaX}$ & Zeolite & 690 & n. a. & 0.74 & 10 & 0.914 & 25 & 120 & 4.373 & (Bellat et al., 2015) \\
\hline $\mathrm{CuX}$ & Zeolite & 653 & n. a. & 0.74 & 10 & 0.914 & 25 & 90 & 3.279 & (Bellat et al., 2015) \\
\hline $\mathrm{NaY}$ & Zeolite & 749 & n. a. & 0.74 & 10 & 0.914 & 25 & 90 & 3.279 & (Bellat et al., 2015) \\
\hline AC fiber & $\mathrm{AC}$ & 1,084 & 0.41 & 0.53 & 3.65 & 0.334 & 26 & 28.2 & 2.815 & (Carter et al., 2011) \\
\hline M-CLZ & Zeolite & 663.2 & 0.298 & n. a. & 46 & 4.204 & 25 & 300.5 & 2.380 & (Kalantarifard et al., 2016) \\
\hline Clinoptilolite & Zeolite & 436.3 & 0.27 & n. a. & 46 & 4.204 & 25 & 194.5 & 1.541 & (Kalantarifard et al., 2016) \\
\hline HKUST-1 & $\mathrm{MOF}$ & 1,733 & 0.89 & $\begin{array}{c}0.54 / \\
0.69\end{array}$ & 0.164 & 0.015 & 23 & 0.504 & 1.120 & This work \\
\hline Faujasite (Y) & Zeolite & 415.2 & 0.136 & n. a. & 46 & 4.204 & 25 & 123.7 & 0.980 & (Kalantarifard et al., 2016) \\
\hline KY & Zeolite & 703 & n. a. & 0.74 & 10 & 0.914 & 25 & 24 & 0.875 & (Bellat et al., 2015) \\
\hline Zeolite A & Zeolite & 301.6 & 0.107 & n. a. & 46 & 4.204 & 25 & 106.7 & 0.845 & (Kalantarifard et al., 2016) \\
\hline S-AP & MS & 422 & 0.72 & 7 & 88 & 8.042 & r. t. & 140.2 & 0.581 & (Nomura and Jones, 2013) \\
\hline Modernite & Zeolite & 253.3 & 0.064 & n. a. & 46 & 4.204 & 25 & 70 & 0.555 & (Kalantarifard et al., 2016) \\
\hline $\begin{array}{l}\text { All-purpose granular } \\
\text { AC (GAC1) }\end{array}$ & $\mathrm{AC}$ & 869 & 0.34 & 0.5 & 3.65 & 0.334 & 26 & 5.30 & 0.529 & (Carter et al., 2011) \\
\hline ED-MIL-101 (Cr)-3 & MOF & 382 & 0.34 & $<2.3$ & 150 & 13.708 & r. t. & 164.9 & 0.401 & (Wang et al., 2016) \\
\hline ED-MIL-101 (Cr)-2 & $\mathrm{MOF}$ & n. a. & n. a. & $<2.3$ & 150 & 13.708 & r. t. & 164.0 & 0.398 & (Wang et al., 2016) \\
\hline S-MAP & MS & 401 & 0.69 & 6.6 & 88 & 8.042 & r. t. & 80.1 & 0.332 & (Nomura and Jones, 2013) \\
\hline ED-MIL-101 (Cr)-1 & MOF & 764 & 0.58 & $<2.3$ & 150 & 13.708 & r. t. & 131.5 & 0.320 & (Wang et al., 2016) \\
\hline
\end{tabular}




\begin{tabular}{|c|c|c|c|c|c|c|c|c|c|c|}
\hline $3 \mathrm{~A}$ & Zeolite & 497 & n. a. & 0.3 & 10 & 0.914 & 25 & 7 & 0.255 & (Bellat et al., 2015) \\
\hline MIL-101 (Cr) & MOF & 2,367 & 1.48 & 2.3 & 150 & 13.708 & r. t. & 100.3 & 0.244 & (Wang et al., 2016) \\
\hline DaY & Zeolite & 717 & n. a. & 0.74 & 10 & 0.914 & 25 & 3.7 & 0.135 & (Bellat et al., 2015) \\
\hline SBA-15 & MS & 922 & 1.14 & 7 & 88 & 0.914 & r. t. & 22 & 0.120 & (Nomura and Jones, 2013) \\
\hline SBA-15 & MS & 595 & 0.4221 & n. a. & 10 & 8.042 & 25 & 3.3 & 0.091 & (Bellat et al., 2015) \\
\hline CBV3020E - Mg & Zeolite & 296 & 0.11 & 0.55 & 0.164 & 0.015 & 23 & 0.035 & 0.078 & This work \\
\hline $\mathrm{AC}$ & $\mathrm{AC}$ & 942 & 0.1011 & n. a. & 10 & 0.914 & 25 & 2 & 0.073 & (Bellat et al., 2015) \\
\hline SBA-16 & MS & 572 & 0.72 & $3.4 / 6.0$ & 0.164 & 0.015 & 23 & 0.029 & 0.064 & This work \\
\hline CBV3020E & Zeolite & 369 & 0.13 & 0.55 & 0.164 & 0.015 & 23 & 0.026 & 0.058 & This work \\
\hline ZSM-5_79 & Zeolite & 348 & 0.18 & 0.55 & 0.164 & 0.015 & 23 & 0.022 & 0.049 & This work \\
\hline ZSM-5_132 & Zeolite & 352 & 0.18 & 0.55 & 0.164 & 0.015 & 23 & 0.015 & 0.033 & This work \\
\hline $\mathrm{AgCu} / \mathrm{HZSM}-5$ & Zeolite & 299 & n. a. & n. a. & 26.2 & 2.394 & RT & $1.62 *$ & 0.023 & (Zhao et al., 2011) \\
\hline ZSM-5_198 & Zeolite & 367 & 0.17 & 0.55 & 0.164 & 0.015 & 23 & 0.01 & 0.022 & This work \\
\hline Ag/HZSM-5 & Zeolite & 310 & n. a. & n. a. & 29.7 & 2.714 & RT & $0.77^{*}$ & 0.009 & (Zhao et al., 2011) \\
\hline Carbopack® B & GCB & 112 & - & - & 0.164 & 0.015 & 23 & 0.004 & 0.009 & This work \\
\hline MIL-53 (Ga) & MOF & 560 & - & n. a. & 10 & 0.914 & 25 & 0.2 & 0.007 & (Bellat et al., 2015) \\
\hline Cu/HZSM-5 & Zeolite & 314 & n. a. & n. a. & 29.6 & 2.705 & RT & $0.49^{*}$ & 0.006 & (Zhao et al., 2011) \\
\hline HZSM-5 (SAR = 360) & Zeolite & n. a. & n. a. & n. a. & 24.4 & 2.230 & RT & $0.35^{*}$ & 0.005 & (Zhao et al., 2011) \\
\hline
\end{tabular}

*Adsorption capacities calculated from $m L$ of catalyst using a zeolite density of $0.72 \mathrm{~g} / \mathrm{mL}$ [16]; *dynamic adsorption capacity; S-AP: primary aminosilica; S-MAP: secondary aminosilica. GCB: graphitised carbon black; MOF: metal organic frameworks; AC: activated carbon; MS: mesoporous Silica. $K_{H}$ has been calculated from the formaldehyde partial pressure employed in each study and the obtained adsorption capacity following the equation 2, assuming that Henry's law can be applied. 


\section{Materials and methods}

\subsection{Commercial materials and synthesis}

Commercially available Carbopack® B (60-80 mesh, SUPELCO), SBA-16 (ACS Materials), HKUST-1 (Basolite ${ }^{\circledR}$ C300, Sigma-Aldrich) and ZSM-5 zeolite (CBV3020E, Zeolyst) were used as received for adsorption tests.

Fluoride-mediated ZSM-5 synthesis was adapted from previous studies [17,18]. In a typical preparation, the aluminium source (different amounts to achieve 200, 150 and $100 \mathrm{Si} / \mathrm{Al}$ mole ratios, respectively) was placed in a $150 \mathrm{~mL}$-Erlenmeyer flask where $50 \mathrm{~mL}$ of distilled water were added under vigorous stirring (700 rpm, room temperature). Subsequently, tetrapropylammonium bromide (TPABr) $(0.498 \mathrm{~g})$ and $\mathrm{NH}_{4} \mathrm{~F}(1.103 \mathrm{~g})$ were added. Finally, $1.607 \mathrm{~g}$ of $\mathrm{SiO}_{2}$ (Aeroperl 300/30, Evonik) was slowly added during $5 \mathrm{~min}$. The as-prepared gel was stirred during $2 \mathrm{~h}$ and finally autoclaved at $443 \mathrm{~K}$ for $144 \mathrm{~h}$. The acidic form was obtained after calcination at $823 \mathrm{~K}$ during $15 \mathrm{~h}$. The samples were labeled as ZSM_198,ZZSM_132 and ZSM_79, respectively; the number indicates the experimentally determined SAR.

MgZSM-5 zeolite was synthetized from commercial H-ZSM-5 zeolite (CBV3020E) following a procedure adapted from $[19,20]$. To this purpose, $2 \mathrm{~g}$ of commercial ZSM-5 zeolite was dispersed in $100 \mathrm{~mL}$ of distilled water and stirred vigorously. Then, the appropriate amount of $\mathrm{Mg}\left(\mathrm{NO}_{3}\right)_{2}$ (4 wt.\% nominal value) was added and the mixture stirred at $70{ }^{\circ} \mathrm{C}$ for $1 \mathrm{~h}$. Afterwards, the solution was dried in a rotavapor at $50{ }^{\circ} \mathrm{C}$ under vacuum until complete evaporation of water. The solid was then dried at $110{ }^{\circ} \mathrm{C}$ overnight and calcined at $550{ }^{\circ} \mathrm{C}$ for $5 \mathrm{~h}$.

\subsection{Materials characterization}

X-ray diffraction patterns were recorded on a Bruker D8 Advance diffractometer, with a Ni detector side filtered $\mathrm{Cu} \mathrm{K} \alpha$ radiation $(1.5406 \AA$ ) over a $2 \theta$ range of 5-60. 
Scanning electron microscopy (SEM) images were acquired in a ZEISS GEMINI SEM 500 microscope using an electron high tension (EHT) voltage ranging from 2 to $6 \mathrm{kV}$. EDX and mapping analyses were performed in the same microscope by using an EDAX SDD detector.

Nitrogen adsorption isotherms for all the adsorbents previously presented were recorded at 77 K using a Micromeritics ASAP 2420 equipment. The specific surface area and pore volume were calculated using the Brunauer-Emmett-Teller (BET) method. Prior to analysis, SBA-16, Carbopack® B and HKUST-1 samples were pre-treated in-situ at $180^{\circ} \mathrm{C}$ for $5 \mathrm{~h}$ under vacuum. Zeolites were pretreated at $250^{\circ} \mathrm{C}$ under vacuum during $10 \mathrm{~h}$.

Zeolite chemical compositions were determined by X-ray fluorescence (XRF) using a XEPOS (AMETEK) device equipped with $\mathrm{Rh}$ radiation tube.

Temperature programmed ammonia desorption $\left(\mathrm{NH}_{3}-\mathrm{TPD}\right)$ was used to evaluate the zeolite acid site density. The experiments were carried out in a Micromeritics AutoChem II 2920 chemisorption analyzer equipped with a TCD detector. Samples were pre-treated in-situ at $550^{\circ} \mathrm{C}$ during $1 \mathrm{~h}$. Once cooled down to room temperature, $5 \% \mathrm{NH}_{3} / \mathrm{He}$ flow was passed through the reactor until saturation. Physisorbed ammonia was removed by flowing an inert gas during a certain time, after which the temperature was gradually increased to $550^{\circ} \mathrm{C}$.

\subsection{Formaldehyde monitoring}

Formaldehyde was on-line monitored using a novel device recently developed and marketed. This instrument was already detailed in our previous studies $[9,21,22]$ so that only a brief description is given. As shown in Figure S1, this analytical method is also based on three highly coupled steps: 1) the uptake of gaseous formaldehyde into an aqueous acetylacetone solution at room temperature through the obtention of an annular diphasic flow, gas and liquid flow rates being fixed at $20 \mathrm{Nml} / \mathrm{min}$ and 17 $\mu \mathrm{L} / \mathrm{min}$, respectively; 2) the chemical reaction between formaldehyde and acetylacetone via the Hantzsch mechanism [23] enhanced at $65^{\circ} \mathrm{C}$ for $3.5 \mathrm{~min}$; and 3) the on-line fluorescence detection of the reaction product, i.e. 3.5-diacetyl-1.4-dihydrolutidine (DDL), DDL being excited by a LED centered at $415 \mathrm{~nm}$ and fluorescence being collected on a photomultiplier (Hamamatsu) coupled to a $530 \pm 40$ 
$\mathrm{nm}$ band pass filter. The commercial formaldehyde analyser ( $\mu$-F1, In'Air Solutions, Strasbourg, France) has a temporal resolution of $2 \mathrm{~s}$, a response time of $10 \mathrm{~min}$ and a detection limit of $1 \mu \mathrm{g} / \mathrm{m}^{3}(0.81$ $\mathrm{ppb})$.

\subsection{Formaldehyde adsorption}

The adsorption experiments were carried out in copper tubes (1/8-inch outer diameter) where each sample was packed and fixed separately by using two quartz wool plugs. These tubes were mounted in the experimental setup schematized in Figure S1. Gaseous formaldehyde (164 ppb) was produced in situ by using a home-made formaldehyde generator. The operating principle of the generator is based on permeation. In order to have the desired formaldehyde concentration, a first synthetic air flow at 10 $\mathrm{NmL} / \mathrm{min}$ was passed first through a formaldehyde aqueous solution $(0.0925 \mathrm{wt} . \%)$ maintained at $20^{\circ} \mathrm{C}$ through a Peltier module and then diluted by using a second synthetic air flow at $390 \mathrm{NmL} / \mathrm{min}$. A resulting formaldehyde gaseous flow of $164 \mathrm{ppb}$ was then generated [21,24]. This generator of known gas concentrations of formaldehyde was previously calibrated by using the conventional sampling method on 2,4-dinitrophenylhydrazine (DNPH) tubes followed by HPLC/UV analysis $[25,26]$. The resulting overall relative uncertainty of the generated gaseous concentration was calculated to be in the range $9-11 \%$.

During the dynamic adsorption experiments, a part of the gaseous formaldehyde mixture was pumped and injected into the tube containing the adsorbent at a flow rate of $15 \mathrm{NmL} / \mathrm{min}$ (mass flow controller 1, see Fig. 1). Since the formaldehyde analyser employed to monitor the gaseous effluent was very sensitive (Limit Of Detection, LOD, $\sim 0.81 \mathrm{ppb}$ ), the tube outlet was diluted with $30 \mathrm{NmL} / \mathrm{min}$ of synthetic air (mass flow controller 2) prior to the analysis in order to be in the linear calibration range and avoid the detector saturation. Afterwards, the effluent gas was continuously sampled and analysed using a formaldehyde analyser.

Prior to each adsorption experiment, the generated gaseous flow was passed through the bypass, diluted and analysed. The obtained intensity corresponds to the initial concentration $\left(C_{0}\right)$ and, therefore, 
it was used as an indicator to determine the necessary time to reach the saturation, i.e. when the outlet concentration was equal to the inlet concentration $\left(C=C_{0}\right)$.

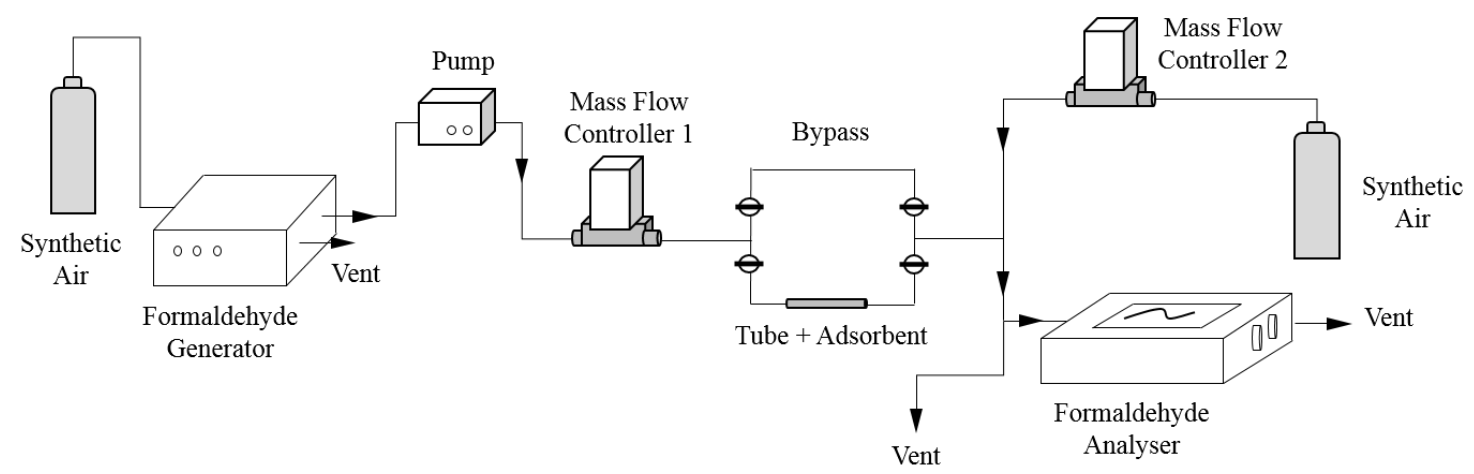

Figure 1. Scheme of the experimental set-up for formaldehyde breakthrough experiments.

\section{Results and discussion}

\subsection{Samples characterization}

Both the commercial adsorbents and as-prepared zeolites were fully characterized in terms of structure, morphology, physicochemical properties, textural properties and acidity in our former studies $[27,28]$. Consequently, these data are only briefly summarized in Table 2.

All as-prepared zeolites exhibit similar pore volume and BET surface thus enabling the solely evaluation of the aluminium content in $\mathrm{HCHO}$ adsorption. As expected, the acid site density decreases when SAR ( $\mathrm{Si} / \mathrm{Al}$ mole ratio) increases since a higher aluminium content implies more bridging hydroxyl groups $\mathrm{Si}-(\mathrm{OH})-\mathrm{Al}$ that act as Brønsted acids. Commercial CBV3020E zeolite exhibits similar specific surface area and slightly higher pore volume which decrease when exchanged with $\mathrm{Mg}$. As previously reported, a decrease in both the specific surface area and pore volume is observed when the zeolite charge compensation cation $\mathrm{H}^{+}$is replaced by a metal cation [10]. This decrease can be due to 
the larger size of magnesium cation compared to the proton. Reasonably, the acid site density (Brønsted acidity) also drops, as a result of the $2 \mathrm{H}^{+} / \mathrm{Mg}^{2+}$ exchange.

Table 2. Textural properties of the investigated adsorbents

\begin{tabular}{|c|c|c|c|c|c|c|c|}
\hline Sample & $\begin{array}{c}S_{B E T} \\
\left(\mathrm{~m}^{2} / \mathrm{g}\right)\end{array}$ & $\begin{array}{c}V_{\text {total }} \\
\left(\mathrm{cm}^{3} / \mathrm{g}\right)\end{array}$ & $\begin{array}{c}V_{m e s o} \\
\left(\mathrm{~cm}^{3} / \mathrm{g}\right)\end{array}$ & $\begin{array}{c}V_{\text {micro }} \\
\left(\mathrm{cm}^{3} / \mathrm{g}\right)\end{array}$ & $\begin{array}{l}D_{\text {pore }} \\
(\mathbf{n m})\end{array}$ & SAR & 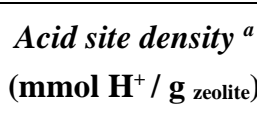 \\
\hline Carbopack ${ }^{\circledR}$ B & 112 & - & - & - & - & - & - \\
\hline SBA-16 & 572 & 0.72 & 0.68 & - & $3.4 / 6.0$ & - & - \\
\hline HKUST-1 & 1733 & 0.89 & 0.14 & 0.68 & $0.54 / 0.69$ & - & - \\
\hline ZSM_198 & 367 & 0.17 & - & 0.07 & - & 198 & 0.132 \\
\hline ZSM_132 & 352 & 0.18 & - & 0.08 & - & 132 & 0.133 \\
\hline ZSM_79 & 348 & 0.18 & - & 0.11 & - & 79 & 0.249 \\
\hline CBV3020E & 369 & 0.26 & - & 0.11 & - & 15 & 0.361 \\
\hline Mg/CBV3020E & 296 & 0.20 & - & 0.10 & - & 15 & 0.280 \\
\hline
\end{tabular}

${ }^{\mathrm{a}}$ Determined by $\mathrm{NH}_{3}$-TPD.

As CBV3020E and $\mathrm{Mg} / \mathrm{CBV} 3020 \mathrm{E}$ samples are reported here for the first time, the corresponding XRD and SEM / EDX analyses are presented in Figure 1. The diffraction patterns of both samples correspond to the sole presence of the MFI structure, characteristic of ZSM-5 zeolites. Neither peaks related to the presence of $\mathrm{Mg}$ precursor, nor $\mathrm{MgO}$ phase could be observed which somehow accounts for the successful $\mathrm{Mg}^{2+}$ cationic exchange within the zeolite frame, thus excluding $\mathrm{MgO}$ presence as segregated phase. Magnesium is uniformly distributed along the zeolite (Fig. 1c) having an experimental metal loading of 3 wt.\% determined by EDX. 


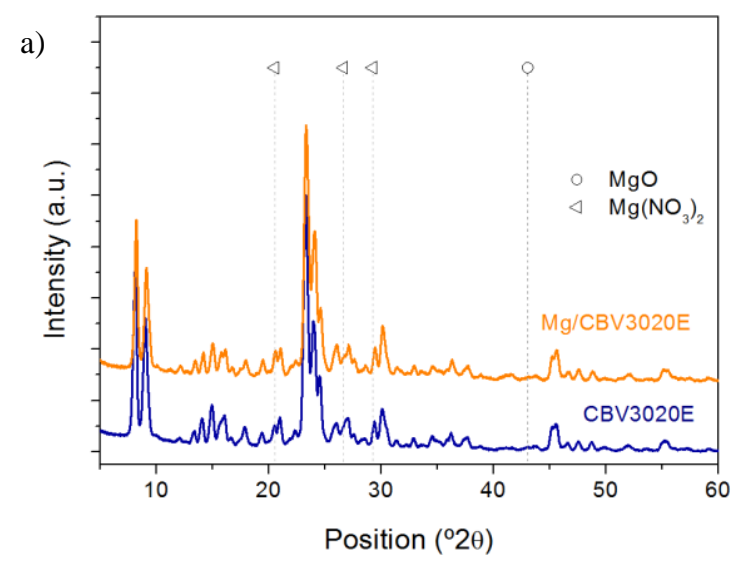

b)

c)
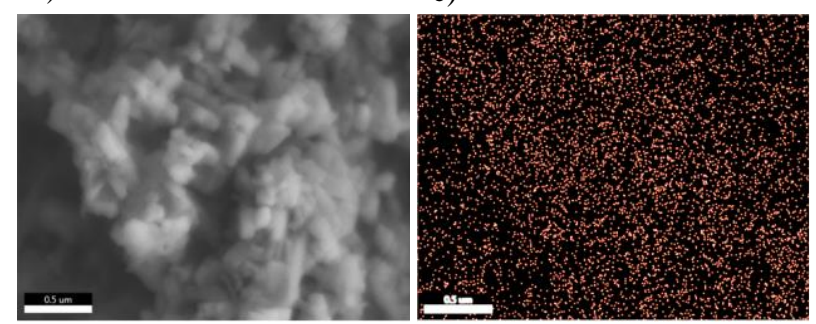

Figure 2. a) X-Ray diffraction patterns of commercial CBV3020E and Mg/CBV3020E. b) and c) Representative SEM micrograph and Mg mapping of Mg/CBV3020E.

\subsection{Evaluation of formaldehyde adsorption capacity of different adsorbents}

Dynamic adsorption experiments were performed to obtain the corresponding breakthrough curves. These breakthrough curves represent the evolution of the adsorbate concentration in the effluent leaving the adsorbent bed as a function of time. In air treatment, the breakthrough time is usually defined at the time in which $5 \%$ of the feed concentration $\left(C_{0}\right)$ is leaving the adsorbent bed and represents the usable capacity of the reactor. Additionally, breakthrough curves allow determining the total adsorption capacity of each material. This capacity can be calculated from each curve using the following equation: 


$$
q=\frac{Q C_{0}}{\mathrm{~m}} \int_{t_{0}}^{t_{s}}\left(1-\frac{C}{C_{0}}\right) d t
$$

where $q$ is the dynamic adsorption capacity per gram of adsorbent, $Q$ is the gas flow rate, $m$ is the mass of adsorbent, $t_{0}$ is the initial time, $t_{\mathrm{s}}$ is the saturation time, $C_{0}$ is the initial concentration, and $C$ is the outlet concentration at a given time.

The error on the calculation of the dynamic adsorption capacity has been estimated as follows:

$$
\frac{\Delta q}{q}=\frac{\Delta Q}{Q}+\frac{\Delta C_{0}}{C_{0}}+\frac{\Delta t}{t}+\frac{\Delta m}{m}
$$

where $\Delta q$ is the error on the adsorption capacity. $\Delta Q$ is the error on the flow rate, $\Delta C_{0}$ is the error on the initial concentration and $\Delta m$ is the error on the adsorbent mass.

\section{Mesoporous silica, graphitised carbon and MOF}

The breakthrough curves obtained for SBA-16, Carbopack® B and HKUST-1 are presented in Figure 3. It is noteworthy that, to enable better graphical comparison of the breakthrough curves, 5.5 $\mathrm{mg}$ of Carbopack ${ }^{\circledR}$ B and SBA-16 were employed for the adsorption tests whereas only $3 \mathrm{mg}$ were used in the case of HKUST-1. 

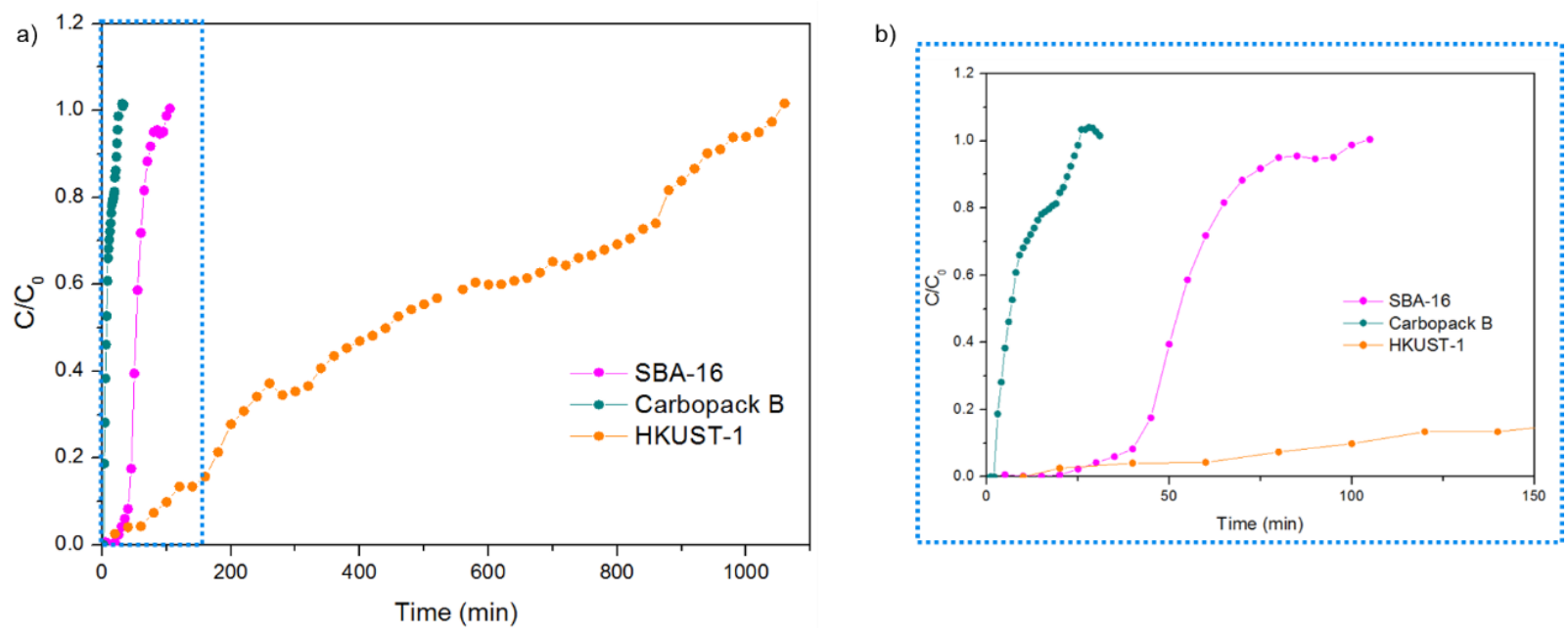

Figure 3. (a) Breakthrough curves of gaseous formaldehyde on Carbopack® B, SBA-16 and HKUST1 (formaldehyde concentration $=164 \mathrm{ppb}$, flow rate $=15 \mathrm{NmL} / \mathrm{min})$ and $(\mathrm{b})$ enlarged view of the first 150 min of the experiment.

As observed in Figure 3a, Carbopack® B and SBA-16 exhibit comparable adsorption profiles while HKUST-1 demonstrates an outstanding adsorption performance despite the smaller adsorbent quantity used. However, Figure $3 \mathrm{~b}$ provides a detailed view of the first $150 \mathrm{~min}$ of the experiment in which an appreciable difference can be observed between Carbopack ${ }^{\circledR}$ B and SBA-16 curves. Carbopack ${ }^{\circledR}$ B shows immediate breakthrough and the outlet concentration sharply increases until the saturation point which is reached after $26 \mathrm{~min}$. This behaviour might be related with the surface chemistry of the graphitised carbon black. Indeed, based on its hydrophobic character, the adsorbateadsorbent interactions should depend solely on London forces. For a small molecule such as formaldehyde, these forces are very weak thus the adsorption of this compound in Carbopack $®$ B is almost negligible. In contrast, SBA-16 needs 34 min to reach the breakthrough most probably due to its higher specific surface area as well as more favourable adsorbate-adsorbent interactions. Formaldehyde molecules can interact with silanol groups $(\mathrm{Si}-\mathrm{OH})$ at the inner surface of SBA-16 mesopores via hydrogen bonding [13], thus promoting their adsorption. As a result, the adsorption capacity of SBA-16 is much higher than that obtained for Carbopack ${ }^{\circledR}$ B (Table ). 
HKUST-1 showed the best adsorption performance among the investigated commercial adsorbents. Despite the HKUST-1 mass employed during the experiment remained the lowest, the breakthrough and saturation points were reached much later. This remarkable capacity can be explained by several factors. HKUST-1 has a very high specific surface area that provides a large amount of adsorption sites and pores with diameters of 5.4 and $6.9 \AA$ suitable for formaldehyde adsorption (kinetic diameter $=2.5 \AA$ ). Additionally, as reported by Dutta et al. [29], a coordination bond between the copper atoms present in the MOF structure and the formaldehyde's carbonyl oxygen can be expected thus contributing to a better adsorption performance. Despite HKUST-1 exhibited an extraordinary adsorption capacity, a significant decrease in formaldehyde adsorption capacity might be expected in humid environments due to its hydrophilic character [30,31].

Table 3. Breakthrough time and adsorption capacities of studied materials towards gaseous formaldehyde

\begin{tabular}{|c|c|c|c|c|c|c|c|c|}
\hline Adsorbent & $C-B^{1,2}$ & SBA-16 2 & HKUST-1 ${ }^{3}$ & ZSM $198^{2}$ & ZSM $132^{2}$ & ZSM $7^{2}$ & $\mathrm{CBV3020E}^{4}$ & $\begin{array}{c}\text { CBV3020E } \\
\mathrm{Mg}^{4}\end{array}$ \\
\hline $\begin{array}{l}\text { Breakth. } \\
\text { time (min) }\end{array}$ & 2 & 32 & 67 & 11 & 12 & 21 & 7 & 4 \\
\hline $\begin{array}{c}\text { Ads. } \\
\text { Capacity }^{4} \\
(\mu \mathrm{g} / \mathrm{g} \text { ads })\end{array}$ & $4.5 \pm 0.6$ & $29.0 \pm 4.1$ & $503.7 \pm 86.8$ & $10.2 \pm 1.4$ & $14.8 \pm 2.0$ & $21.6 \pm 3.0$ & $26.0 \pm 5.6$ & $34.9 \pm 8.0$ \\
\hline
\end{tabular}

\section{Zeolites}

Formaldehyde dynamic adsorption experiments were carried out over three synthetic zeolites with different SAR (Figure 3). The shape of the obtained breakthrough curves is fairly similar in all cases. The adsorption of formaldehyde was complete during the first minutes, the breakthrough point being reached at 11, 12 and 21 min for ZSM-5_198, ZSM-5_132 and ZSM-5_79, respectively. Zeolites with higher SAR exhibited earlier breakthrough most probably due to the difficulty of formaldehyde molecules to find adsorption sites. By contrast, ZSM-5_79 almost doubling the acid sites showed a longer breakthrough. After the breakthrough point, two different slopes can be distinguished thus informing about a different kinetic behavior. Firstly, a sharp increase in the outlet concentration is 
observed which indicates fast kinetics followed by a continuous but slow increment of the concentration until the initial concentration is reached, suggesting that the adsorption kinetics close to the adsorbent saturation is much slower. Adsorption capacities were assessed by numerical integration of the area above the breakthrough curve and are also presented in Table .

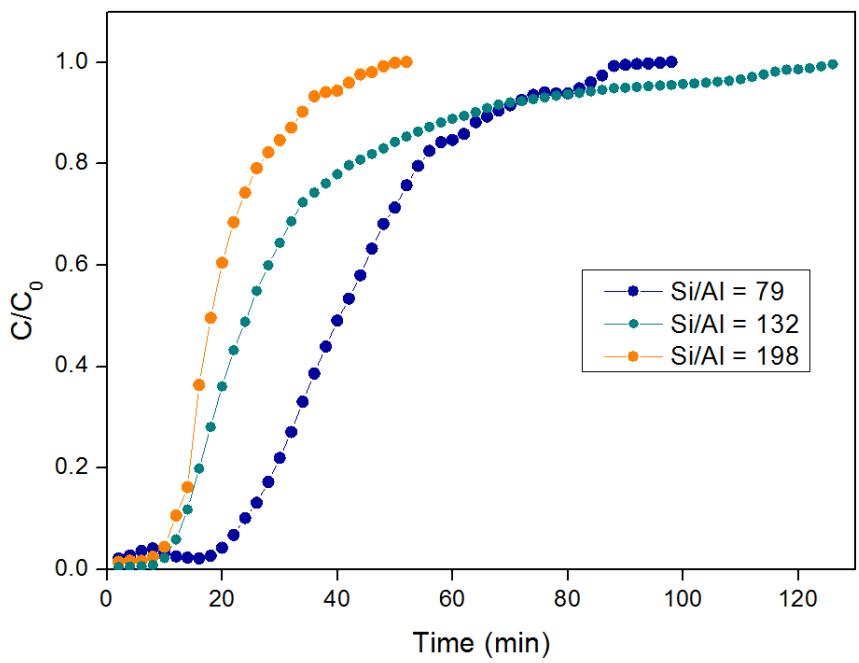

Figure 4. Breakthrough curves of gaseous formaldehyde over ZSM-5 zeolites with different Si/Al ratios (formaldehyde concentration $=164 \mathrm{ppb}$, flow rate $=15 \mathrm{NmL} / \mathrm{min}$ ).

It can be concluded therefore that zeolites with higher acid density, i.e. lower Si/Al ratio, exhibit greater adsorption capacity. Based on the latter observation, it appears that the adsorption of formaldehyde molecules is directly related to the aluminium content and thus to the amount of Brønsted acid sites. In order to illustrate this relationship, adsorption capacities of the investigated ZSM-5 zeolites including the commercial CBV3020E $(\mathrm{Si} / \mathrm{Al}=15)$ were plotted versus SAR (Figure 5). A linear correlation is evidenced suggesting that formaldehyde adsorption is directly related with $\mathrm{Al}$ concentration. These results are in line with earlier IR spectroscopic studies of formaldehyde adsorption on ZSM-5 zeolites in which it was demonstrated that formaldehyde interacts with $\mathrm{Si}-\mathrm{OH}-\mathrm{Al}$ groups by hydrogen bonding [32]. Therefore, the adsorption process seems to be ruled by the interactions between the formaldehyde's carbonyl function and the bridging $\mathrm{Si}-(\mathrm{OH})-\mathrm{Al}$ zeolite groups. On the other hand, the reduction of the specific surface area observed when SAR decreases appears to have a negligible effect on formaldehyde adsorption. This observation reinforces the idea that formaldehyde adsorption is primarily dominated by surface chemistry. Therefore, it can be concluded that, at low concentrations, 
a more effective formaldehyde adsorption can be achieved by using zeolites with high aluminium content.

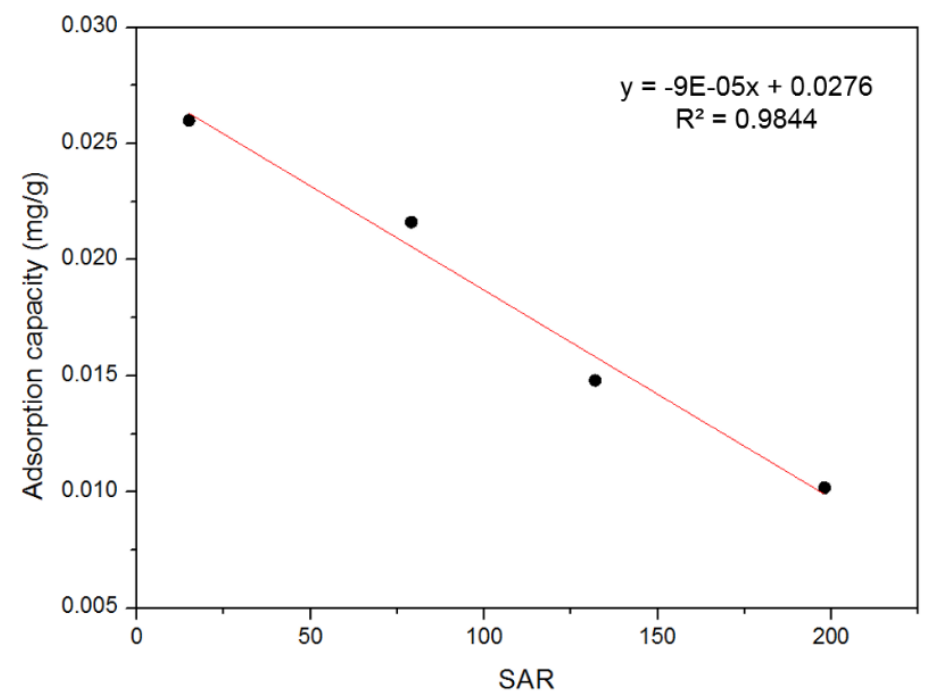

Figure 5. Formaldehyde adsorption capacities obtained over ZSM-5 zeolites with different Si/Al ratios.

In order to further evaluate the influence of surface chemistry on formaldehyde adsorption, breakthrough experiments were conducted over commercial CBV3020E and Mg/CBV3020E (Figure 6). Apparently, both curves are very similar however it should be taken into account that the employed masses for the tests were slightly different, 1.8 and $1.6 \mathrm{mg}$ for CBV3020E and Mg/CBV3020E, respectively. Therefore, a slight difference between the curves could represent a great variation in the adsorption capacity. Breakthrough times obtained for pristine and metal loaded zeolite were 7 and 4 min, respectively. The shorter breakthrough time of Mg/CBV3020E could be attributed to both the lower mass of the sample and the lower specific surface area. Regarding kinetics, both zeolites showed similar behaviour until $\mathrm{C} / \mathrm{C}_{0}$ reached $\sim 0.5$. From this point to the saturation, $\mathrm{Mg} / \mathrm{CBV} 3020 \mathrm{E}$ exhibited slower kinetics, presumably due to the diffusional limitations induced by the presence of large magnesium cations. 


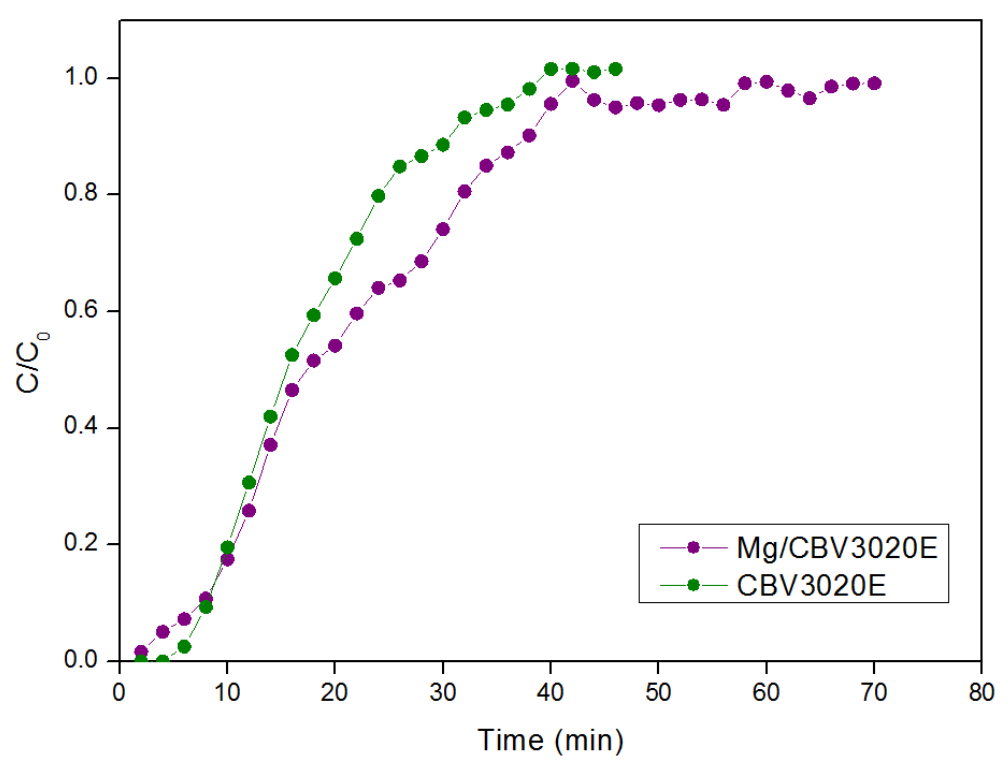

Figure 6. Breakthrough curves of gaseous formaldehyde over CBV3020E and CBV3020E-Mg zeolites $\left(\mathrm{C}_{0}=\right.$ $164 \mathrm{ppb}$, flow rate $=15 \mathrm{NmL} / \mathrm{min})$.

A positive variation in the adsorption capacity (34\%) is evidenced after $\mathrm{Mg}$ cationic exchange. This enhancement in the capacity suggests that formaldehyde establishes stronger interactions with $\mathrm{Mg}^{2+}$ than with $\mathrm{H}^{+}$, results that are in line with those reported by Bellat et al. [10]. They observed that the presence of different cations such as $\mathrm{Na}^{+}, \mathrm{K}^{+}$or $\mathrm{Cu}^{2+}$ in FAU-type zeolites led to an improvement in the formaldehyde adsorption capacity. As aforementioned for as-prepared zeolites, a decrease in the specific surface area does not significantly affect the adsorption ability, providing a compelling evidence of the importance of surface chemistry on formaldehyde adsorption.

\section{Comparison between different adsorbents}

Motivated by its occurrence in indoor air and the harmful effects that causes, formaldehyde adsorption has been studied over a wide variety of different materials such as MOF, zeolites, AC and mesoporous silica (see Table 1). As shown in Figure 7, most studies are conducted at formaldehyde concentrations from 3.65 to $150 \mathrm{ppm}$ (corresponding to partial pressures from 0.015 to $13.7 \mathrm{~Pa}$ ), thus being not representative of ambient conditions where formaldehyde is usually present at several tens or 
few hundreds of ppb. Moreover, comparing experimental data obtained at different partial pressures can result in an inaccurate evaluation of the adsorption performance.

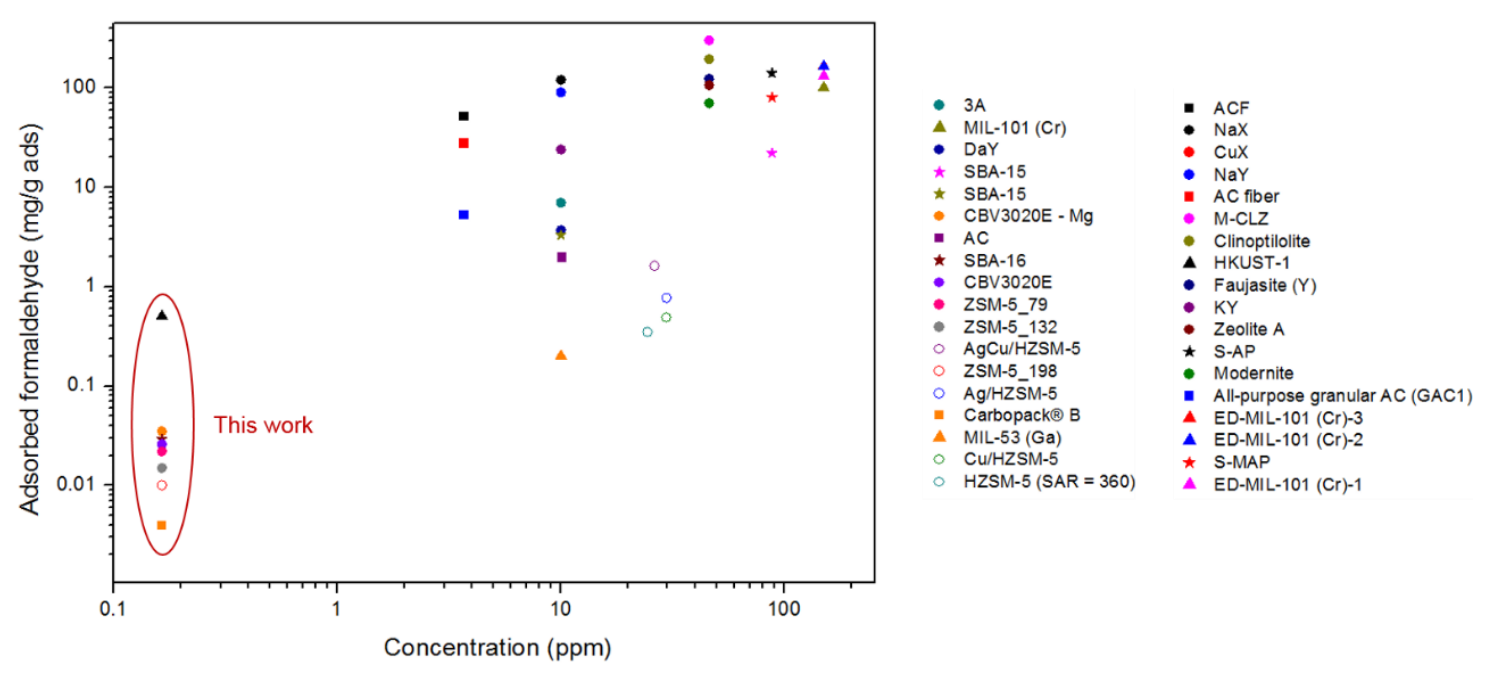

Figure 7. Formaldehyde adsorption capacities of diverse materials at different formaldehyde concentrations

In order to minimize the possible errors, the Henry constant $\left(K_{H}\right)$ is commonly employed for comparison purposes instead of adsorption capacity [33-36]. $K_{H}$ is a relevant parameter used to explain the gas-solid adsorption behaviour [33] that allows to evaluate the adsorption affinity of a material for a certain adsorbate. However, there are some limitations in the use of this constant. Henry's law establishes that the adsorbate should neither undergo any chemical reaction with the sorbent nor dissociation when adsorbed. This is not always the case in formaldehyde adsorption where chemisorption frequently takes place due to the presence of the carbonyl group. In other cases, polymerization reactions [10] or self-catalytic oxidation-reduction reactions have been observed as a consequence of extremely low adsorption kinetics which can lead to several days to reach the equilibrium $[37,38]$. Besides, this parameter is considered valid only at relatively low pressures $(<100$ Pa corresponding to $\sim 1,094 \mathrm{ppm})$, where it is assumed that the adsorption capacity increases linearly with adsorbate partial pressure. Hence, only in this interval, Henry's law can be applied [35] and $K_{H}$ (mol/kg Pa) estimated by plotting the adsorption capacity versus partial pressure according with the following equation: 


$$
K_{H}=\frac{q}{P_{f} M_{f}}
$$

where $q\left(\mathrm{~kg} / \mathrm{kg}\right.$ adsorbent) is the adsorption capacity, $P_{f}$ is the formaldehyde partial pressure $(\mathrm{Pa})$ and $M_{f}$ is the molecular weight of formaldehyde $(\mathrm{kg} / \mathrm{mol})$.

In most studies, Henry constant is not provided; it has therefore been calculated whenever possible from the published data available. In Table 1, experimental data are listed in decreasing order of Henry constant. The determination of $K_{H}$ values also enables to draw some general conclusions about the most crucial factors impacting the formaldehyde adsorption. Similarly to the trend observed in zeolites, SSA (specific surface area) does not seem to be one of the most important factors on formaldehyde adsorption capacity as elucidated by a relatively low $K_{H}$ of MIL-101 (Cr) (SSA = 2,367 $\left.\mathrm{m}^{2} \mathrm{~g}^{-1}\right)$ and the high $K_{H}$ obtained for S-AP $\left(\mathrm{SSA}=422 \mathrm{~m}^{2} \mathrm{~g}^{-1}\right)$. Considering the pore size, it appears to be relevant when it is in the same order as formaldehyde molecule diameter $\left(D_{p}=0.25 \mathrm{~nm}\right)$ due to the steric hindrance that can be caused, as observed in zeolite $3 \mathrm{~A}\left(D_{p}=0.3 \mathrm{~nm}\right)[10]$. However, it does not appear to be significant when it is much larger, as confirmed by the different $K_{H}$ values obtained for $\mathrm{NaY}\left(D_{p}=0.74 \mathrm{~nm}, K_{H}=0.135 \mathrm{~mol} / \mathrm{kg} \mathrm{Pa}\right)$ and $\mathrm{NaX}\left(D_{p}=0.74 \mathrm{~nm}, K_{H}=4.373 \mathrm{~mol} / \mathrm{kg} \mathrm{Pa}\right)$, thus confirming that surface chemistry i.e. adsorbate-adsorbent interactions governs the adsorption of formaldehyde.

As evidenced by $K_{H}$ values, activated carbon fibers and some of metal loaded FAU zeolites exhibited an outstanding affinity to formaldehyde attributed to the formation of strong adsorbateadsorbent interactions. Therefore, higher formaldehyde adsorption capacity is expected even at low concentrations, making these materials potential candidates for pollutant removal purposes. Nevertheless, these metal loaded zeolites are considerably hydrophilic therefore exhibiting high selectivity for water at low concentrations as recently reported [39]. Consequently, their use in humid environments is conditioned upon adding an upstream device for water trapping. Concerning gas analysis applications, these adsorbents are probably not suitable since a complete desorption is required for an accurate formaldehyde quantification. Related to this, Bellat et al. [10] observed that the adsorbed 
formaldehyde can polymerize into paraformaldehyde in the cages of $\mathrm{NaX}$ and $\mathrm{NaY}$ zeolites . The complete polymer desorption becomes much more difficult due to its size, being only possible at 400 ${ }^{\circ} \mathrm{C}$ under dynamic vacuum, which is not compatible with gas analysis applications. Formaldehyde desorption from $\mathrm{AC}$ fibers was not investigated but the strong interactions of this compound with the acidic groups could potentially result in higher desorption temperatures. Therefore, for these applications, moderate adsorbate-adsorbent interactions are preferred. Hence, adsorbents showing $K_{H}$ values from 0.1 to $1.5 \mathrm{~mol} / \mathrm{kg} \mathrm{Pa}$ are expected to be more appropriate. These adsorbents exhibited a non-negligible formaldehyde adsorption capacity, thus being suitable for pollutant removal and enabling a quantitative sampling for gas analysis applications. Furthermore, the intermediate strength of the interactions may presumably lead to less extreme conditions for desorption compared to the metal loaded FAU zeolites, thereby facilitating adsorbent regeneration. In this context, HKUST-1 could be a suitable candidate for this application. In this MOF, water molecules are adsorbed by interactions with copper sites and the carboxylic groups of the linkers and, since formaldehyde is a molecule of similar structure and polarity, comparable interactions are expected in formaldehyde adsorption. It may be reasonable to think that formaldehyde desorption can be accomplished at moderate temperatures $\left(\sim 120{ }^{\circ} \mathrm{C}\right)$, as in the case of water [30].

Finally, $K_{H}$ values lower than $0.1 \mathrm{~mol} / \mathrm{kg} \mathrm{Pa}$ are found for considerably hydrophobic materials such as ZSM-5 zeolites [40], certain mesoporous silica [41] and Carbopack® B [42] due to the weakness of the adsorbate-adsorbent interactions. It is obvious that these materials are not suitable for pollutant removal on large scale because of their limited adsorption capacity at low concentrations. However, some of them, such as Mg loaded and low SAR ZSM-5 zeolites or mesoporous silica (SBA-15 and SBA-16), can be used as a formaldehyde scrubber to be integrated in the formaldehyde analyser employed in this work. As illustrated in Figure S1, in this instrument a DNPH cartridge (see Figure S1) is employed to generate zero formaldehyde air flow required for the blank. This cartridge costs $\sim 15 €$ and has a formaldehyde adsorption capacity of $75 \mu \mathrm{g}$ (Waters Corporation, Milford, MA, USA). If formaldehyde ambient concentration is equal to $164 \mathrm{ppb}\left(201.4 \mu \mathrm{g} / \mathrm{m}^{3}, \mathrm{~T}=25{ }^{\circ} \mathrm{C}\right)$ and the analyser operates with a sampling flow rate of $20 \mathrm{~mL} / \mathrm{min}$, the lifespan can be calculated as follows: 


$$
t=\frac{q_{t}}{C \times Q}
$$

Where $t$ is the lifespan (min), $q_{t}$ is the total capacity of the cartridge $(\mu \mathrm{g}), C$ is the formaldehyde concentration in the air flow $\left(\mu \mathrm{g} / \mathrm{m}^{3}\right)$ and $Q$ is the flow rate $(\mathrm{mL} / \mathrm{min})$. Using the abovementioned conditions, the lifespan of a DNPH commercial tube has been calculated to be 13 days. Instead of using these commercial cartridges, a similar cartridge can be filled with $10 \mathrm{~g}$ of $\mathrm{Mg} / \mathrm{HZSM}-5$ giving a total formaldehyde adsorption capacity of $349 \mu \mathrm{g}$ per cartridge. Under the same conditions, this consumable could be used for 60 days thus largely improving the lifespan of the commercial one. Additionally, since the price of ZSM-5 zeolites is extremely low (1-3 €/kg, Zeolyst International) compared to other adsorbent materials, the cost of these consumables could be drastically reduced.

\section{Conclusions}

Thanks to the recent development of a new formaldehyde analyser operating in near real time and enabling to quantify very low concentrations of gaseous formaldehyde $[21,22]$, the formaldehyde adsorption capacities of a series of materials differing in structure, porosity and chemical composition have been evaluated at realistic concentrations. Among them, HKUST-1 demonstrated to be the most efficient adsorbent for formaldehyde capture at ppb levels. This outstanding capacity is presumably ascribed to the strong adsorbate-adsorbent interactions between copper centres and formaldehyde's carbonyl group. However, as formaldehyde molecules, water molecules can be easily coordinated on the unsaturated copper sites of HKUST-1, therefore, a significant decrease of the formaldehyde adsorption capacity in humid environments could be envisaged, limiting its use in these conditions. In gas analysis, this disadvantage can be partially overcome by adding a water-trapping device prior to the gas sampling on the adsorbent bed, as can be for example a Nafion tube. To avoid the need to integrate water-trapping devices, more hydrophobic adsorbents such as ZSM-5 zeolites could be preferred. Formaldehyde adsorption over these zeolites is directly related to the aluminium content suggesting that formaldehyde adsorption occurs on Brønsted acid centres. Despite the moderate adsorption capacity of 
ZSM-5 zeolites compared to HKUST-1 that could prevent their use for pollutant removal on large scale, zeolites can be considered for gas analysis applications. In this work, it has been demonstrated that this material can be employed to manufacture formaldehyde scrubbers with a 60 days lifespan in polluted environments $\left(\mathrm{C}_{\mathrm{HCHO}}=164 \mathrm{ppb}\right)$. This result represents a considerable improvement with respect to the lifespan of the current scrubber (13 days) and can be manufactured at a highly competitive price.

\section{Acknowledgments}

This project has been supported by the European Union's through the LIFE SMART IN'AIR - Smart indoor air monitoring network to reduce the impacts of pollutants on environment and health - under grant number LIFE17 ENV/FR/000330.

\section{References}

[1] T. Salthammer, S. Mentese, R. Marutzky, Formaldehyde in the Indoor Environment, Chemical Reviews. 110 (2010) 2536-2572. https://doi.org/10.1021/cr800399g.

[2] T. Salthammer, Formaldehyde sources, formaldehyde concentrations and air exchange rates in European housings, Building and Environment. 150 (2019) 219-232. https://doi.org/10.1016/j.buildenv.2018.12.042.

[3] B. Wang, S.C. Lee, K.F. Ho, Characteristics of carbonyls: Concentrations and source strengths for indoor and outdoor residential microenvironments in China, Atmospheric Environment. 41 (2007) 2851-2861. https://doi.org/10.1016/j.atmosenv.2006.11.039.

[4] M. Hauptmann, J.H. Lubin, P.A. Stewart, R.B. Hayes, A. Blair, Mortality from Solid Cancers among Workers in Formaldehyde Industries, Am J Epidemiol. 159 (2004) 1117-1130. https://doi.org/10.1093/aje/kwh174.

[5] S. Suresh, T.J. Bandosz, Removal of formaldehyde on carbon -based materials: A review of the recent approaches and findings, Carbon. 137 (2018) 207-221. https://doi.org/10.1016/j.carbon.2018.05.023.

[6] G.M. Marsh, A.O. Youk, J.M. Buchanich, S. Erdal, N.A. Esmen, Work in the metal industry and nasopharyngeal cancer mortality among formaldehyde-exposed workers, Regulatory Toxicology and Pharmacology. 48 (2007) 308-319. https://doi.org/10.1016/j.yrtph.2007.04.006.

[7] W.H.O.R.O. for Europe, Air Quality Guidelines for Europe, WHO Regional Office Europe, 2000.

[8] Décret $n^{\circ}$ 2011-1727 du 2 décembre 2011 relatif aux valeurs-guides pour l'air intérieur pour le formaldéhyde et le benzène, 2011.

[9] M. Guglielmino, A. Allouch, C.A. Serra, S.L. Calvé, Development of microfluidic analytical method for on-line gaseous Formaldehyde detection, Sensors and Actuators B: Chemical. 243 (2017) 963-970. https://doi.org/10.1016/j.snb.2016.11.093. 
[10] J.-P. Bellat, I. Bezverkhyy, G. Weber, S. Royer, R. Averlant, J.-M. Giraudon, J.-F. Lamonier, Capture of formaldehyde by adsorption on nanoporous materials, Journal of Hazardous Materials. 300 (2015) 711-717. https://doi.org/10.1016/j.jhazmat.2015.07.078.

[11] E.M. Carter, L.E. Katz, G.E. Speitel, D. Ramirez, Gas-Phase Formaldehyde Adsorption Isotherm Studies on Activated Carbon: Correlations of Adsorption Capacity to Surface Functional Group Density, Environ. Sci. Technol. 45 (2011) 6498-6503. https://doi.org/10.1021/es104286d.

[12] A. Kalantarifard, J.G. Gon, G.S. Yang, Formaldehyde Adsorption into Clinoptilolite Zeolite Modified with the Addition of Rich Materials and Desorption Performance Using Microwave Heating, in: 2016. https://doi.org/10.3319/tao.2016.05.28.01(tt).

[13] A. Nomura, C.W. Jones, Amine-Functionalized Porous Silicas as Adsorbents for Aldehyde Abatement, ACS Appl. Mater. Interfaces. 5 (2013) 5569-5577. https://doi.org/10.1021/am400810s.

[14] Z. Wang, W. Wang, D. Jiang, L. Zhang, Y. Zheng, Diamine-appended metal-organic frameworks: enhanced formaldehyde-vapor adsorption capacity, superior recyclability and water resistibility, Dalton Trans. 45 (2016) 11306-11311. https://doi.org/10.1039/C6DT01696K.

[15] A. Kapoor, R.T. Yang, Correlation of equilibrium adsorption data of condensible vapours on porous adsorbents, Gas Separation \& Purification. 3 (1989) 187-192. https://doi.org/10.1016/0950-4214(89)80004-0.

[16] ZSM-5 Catalyst Supplier - Molecular Sieves - ACS Material, (n.d.). https://www.acsmaterial.com/zsm-5-catalyst-1122.html (accessed June 29, 2019).

[17] F.L. Bleken, S. Chavan, U. Olsbye, M. Boltz, F. Ocampo, B. Louis, Conversion of methanol into light olefins over ZSM-5 zeolite: Strategy to enhance propene selectivity, Applied Catalysis A: General. 447-448 (2012) 178-185. https://doi.org/10.1016/j.apcata.2012.09.025.

[18] P. Losch, A.B. Pinar, M.G. Willinger, K. Soukup, S. Chavan, B. Vincent, P. Pale, B. Louis, HZSM-5 zeolite model crystals: Structure-diffusion-activity relationship in methanol-to-olefins catalysis, Journal of Catalysis. 345 (2017) 11-23. https://doi.org/10.1016/j.jcat.2016.11.005.

[19] A.J. Maia, B. Louis, Y.L. Lam, M.M. Pereira, Ni-ZSM-5 catalysts: Detailed characterization of metal sites for proper catalyst design, Journal of Catalysis. 269 (2010) 103-109. https://doi.org/10.1016/j.jcat.2009.10.021.

[20] V. Kazansky, A. Serykh, A new charge alternating model of localization of bivalent cations in high silica zeolites with distantly placed aluminum atoms in the framework, Microporous and Mesoporous Materials. 70 (2004) 151-154. https://doi.org/10.1016/j.micromeso.2004.02.004.

[21] M. Guglielmino, P. Bernhardt, C. Trocquet, C.A. Serra, S. Le Calvé, On-line gaseous formaldehyde detection by a microfluidic analytical method based on simultaneous uptake and derivatization in a temperature controlled annular flow, Talanta. 172 (2017) 102-108. https://doi.org/10.1016/j.talanta.2017.05.038.

[22] C. Trocquet, P. Bernhardt, M. Guglielmino, I. Malandain, C. Liaud, S. Englaro, S. Le Calvé, Near Real-Time Monitoring of Formaldehyde in a Low-Energy School Building, Atmosphere. 10 (2019) 763. https://doi.org/10.3390/atmos10120763.

[23] Ulli. Eisner, Josef. Kuthan, Chemistry of dihydropyridines, Chem. Rev. 72 (1972) 1-42. https://doi.org/10.1021/cr60275a001.

[24] A. Becker, C. Andrikopoulou, P. Bernhardt, R. Ocampo-Torres, C. Trocquet, S. Le Calvé, Development and Optimization of an Airborne Formaldehyde Microfluidic Analytical Device Based on Passive Uptake through a Microporous Tube, Micromachines. 10 (2019) 807. https://doi.org/10.3390/mi10120807.

[25] L. Allou, L. El Maimouni, S. Le Calvé, Henry's law constant measurements for formaldehyde and benzaldehyde as a function of temperature and water composition, Atmospheric Environment. 45 (2011) 2991-2998. 
[26] C. Marchand, S. Le Calve, P. Mirabel, N. Glasser, A. Casset, N. Schneider, F. De Blay, Concentrations and determinants of gaseous aldehydes in 162 homes in Strasbourg (France), Atmospheric Environment. 42 (2008) 505-516.

[27] I. Lara-Ibeas, C. Megías-Sayago, A. Rodríguez-Cuevas, R. Ocampo-Torres, B. Louis, S. Colin, S. Le Calvé, Adsorbent screening for airborne BTEX analysis and removal, Journal of Environmental Chemical Engineering. (2019) 103563. https://doi.org/10.1016/j.jece.2019.103563.

[28] C. Megías-Sayago, I. Lara-Ibeas, Q. Wang, S. Le Calvé, B. Louis, Volatile organic compounds (VOCs) removal capacity of ZSM-5 zeolite adsorbents for near real-time BTEX detection, Journal $\begin{array}{llllll}\text { of } & \text { Environmental } & \text { Chemical } & \text { Engineering. } & 8 & \text { (2020) }\end{array}$ https://doi.org/10.1016/j.jece.2020.103724.

[29] T. Dutta, K.-H. Kim, R.J.C. Brown, Y.-H. Kim, D. Boukhvalov, Metal-organic framework and Tenax-TA as optimal sorbent mixture for concurrent GC-MS analysis of C1 to C5 carbonyl compounds, Scientific Reports. 8 (2018) 5033. https://doi.org/10.1038/s41598-018-23391-6.

[30] Z. Zhao, S. Wang, Y. Yang, X. Li, J. Li, Z. Li, Competitive adsorption and selectivity of benzene and water vapor on the microporous metal organic frameworks (HKUST-1), Chemical Engineering Journal. 259 (2015) 79-89. https://doi.org/10.1016/j.cej.2014.08.012.

[31] P. Küsgens, M. Rose, I. Senkovska, H. Fröde, A. Henschel, S. Siegle, S. Kaskel, Characterization of metal-organic frameworks by water adsorption, Microporous and Mesoporous Materials. 120 (2009) 325-330. https://doi.org/10.1016/j.micromeso.2008.11.020.

[32] E. Kukulska-Zając, J. Datka, Transformations of Formaldehyde Molecules in Cu-ZSM-5 Zeolites, J. Phys. Chem. C. 111 (2007) 3471-3475. https://doi.org/10.1021/jp066732g.

[33] E. Ahmed, A. Deep, E.E. Kwon, R.J.C. Brown, K.-H. Kim, Performance comparison of MOF and other sorbent materials in removing key odorants emitted from pigpen slurry, Scientific Reports. 6 (2016) 31283. https://doi.org/10.1038/srep31283.

[34] C.-J. Na, M.-J. Yoo, D.C.W. Tsang, H.W. Kim, K.-H. Kim, High-performance materials for effective sorptive removal of formaldehyde in air, Journal of Hazardous Materials. 366 (2019) 452-465. https://doi.org/10.1016/j.jhazmat.2018.12.011.

[35] J.E. Szulejko, K.-H. Kim, J. Parise, Seeking the most powerful and practical real-world sorbents for gaseous benzene as a representative volatile organic compound based on performance metrics, Separation and Purification Technology. 212 (2019) 980-985. https://doi.org/10.1016/j.seppur.2018.11.001.

[36] K. Vellingiri, P. Kumar, A. Deep, K.-H. Kim, Metal-organic frameworks for the adsorption of gaseous toluene under ambient temperature and pressure, Chemical Engineering Journal. 307 (2017) 1116-1126. https://doi.org/10.1016/j.cej.2016.09.012.

[37] H. Nakayama, A. Hayashi, T. Eguchi, N. Nakamura, M. Tsuhako, Adsorption of formaldehyde by polyamine-intercalated $\alpha$-zirconium phosphate, Solid State Sciences. 4 (2002) 1067-1070. https://doi.org/10.1016/S1293-2558(02)01367-5.

[38] Y. Zhang, J. Yi, Q. Xu, Studies on adsorption of formaldehyde in zirconium phosphateglyphosates, Solid State Sciences. $13 \quad$ (2011) 54-58. https://doi.org/10.1016/j.solidstatesciences.2010.10.008.

[39] J.-P. Bellat, G. Weber, I. Bezverkhyy, J.-F. Lamonier, Selective adsorption of formaldehyde and water vapors in $\mathrm{NaY}$ and $\mathrm{NaX}$ zeolites, Microporous and Mesoporous Materials. 288 (2019) 109563. https://doi.org/10.1016/j.micromeso.2019.109563.

[40] D.P. Serrano, G. Calleja, J.A. Botas, F.J. Gutierrez, Characterization of adsorptive and hydrophobic properties of silicalite-1, ZSM-5, TS-1 and Beta zeolites by TPD techniques, $\begin{array}{llllll}\text { Separation } & \text { and } & \text { Purification } & \text { (2007) }\end{array}$ https://doi.org/10.1016/j.seppur.2006.08.013. 
[41] D.P. Serrano, G. Calleja, J.A. Botas, F.J. Gutierrez, Adsorption and Hydrophobic Properties of Mesostructured MCM-41 and SBA-15 Materials for Volatile Organic Compound Removal, Ind. Eng. Chem. Res. 43 (2004) 7010-7018. https://doi.org/10.1021/ie040108d.

[42] B. Tolnai, G. Barkó, J. Hlavay, A. Gelencsér, Evaluation of Carbopack B adsorbent for the tubetype diffusive sampling of volatile organic compounds at ambient concentration, Analyst. 124 (1999) 1859-1863. https://doi.org/10.1039/A907872J. 